\section{CASES FROM PRACTICE.}

\section{ME D I C O-L EGA L N O TES. \\ By R. F. Hutchinsan, M.D., Civil Surgeon of Patna.}

As the following case is important in its medico-legal bearings, I extract it entire from my post-mortem book.

I. "Body of Chummun Chamar, said to have been killed by blows with a split bamboo. After the beating he went to his own house and died, the distance traversed being half a mile (pao koss.) He said nothing, but died almost immediately.

"External appearances. - Body that of an old man, somewhat emaciated, but in good condition. Face placid. Digested food issuing from mouth. There are few peculiar white parallel striæ across abdomen, between sternum and umbilicus. To right of median line, and four inches below right nipple, there is a striated bruise $1 \frac{1}{2}$ inches square, the striæ running downwards and inwards; and below them one short transverse mark, threefourths of an inch long. Slight bruise at back of right elbow. Nothing more.

"Internal appearance.-On exposing the ribs, I find fracture of the 7 th and 8 th on each side, the fractures on both sides being close to the cartilages; on the right side there is slight depression of the fracture end. Thoracic organs healthy.

"On opening abdomen, there is a great escape of fluid blood, leading me to anticipate rupture of the spleen; and on reflecting the abdominal walls, I find that the spleen, slightly enlarged, is ruptured at its lower end, anteriorly. There is an enormous rupture of the higher surface of right lube of liver, the lobe being all but divided transversely by a bifurcated rupture, 8 inches long, $1 \frac{1}{2}$ inches deep and broad. There is a small superficial rupture above, and at right angles to the larger one. Other organs healthy."

The main objects of interest in this case are-

1st. An old man with four ribs fractured, and liver and spleen ruptured, can walk home half a mile, the wonder being that he could walk at all, or even leave the ground on which he lay.

$2 n d$. Fracture of two ribs and rupture of the spleen can exist without any external mark whatever.

II. After examining seyeral cases of hanging, suicidal and judicial, I have noticed two appearances invariably present in male cases. The first of these would also be present in females, were it not for the difference in their dress. Both indications are valuable, as betokening suspension during life, and, as far as I can make out, have not been noticed by any writers. The first is the flow of saliva out of the mouth, down the chin, and straight down the chest. The appearance is unmistakeable and invariable, and could not occur in a body hung up after death, the secretion of saliva being a living act. Of course this sign is best seen on the naked chest, and in ninety-nine out of a hundred cases the chest is exposed, for the suicide hangs himself with his chudder, and criminals are hung in their dhotees only. I have seen the saliva line even on a koorta, and on one occasion the drip took place through the execution cap.

The second appearance is only seen in male cases, and is almost equally invariable; where it is not present, a sign equally valuable, as indicating suspension during life, takes its place. The rule is, the habitual discharge of semen during the last struggle; the exception, the passage of urine

The latter indication is valuable in the case of females, but it only occurs in either sex when there has been no micturition previous to suspension.

Should either appearance be present, hanging must have taken place during life, and the absence of both must indicate suspension after death.

III. I availed myself of a recent opportunity to ascertain exactly the amount of wood which would be necessary to destroy entirely an adult, healthy body, and the time that would be necessary for its complete cremation. The pyre was composed of ten maunds of wood, but an equal amount of jala's straw was necessary, as also two bottles of oil. The pile was lighted at $6.30 \mathrm{p} . \mathrm{m}$. and at $3 \mathrm{a} . \mathrm{m}$, next morning, the consumption of the body was declared to be complete When I visited the spot, I found in the centre of the ashes the heads of both femora entire, but completely calcined, and a mass of incinerated matter as large as two fists, said to be the remains of the liver.
Thus twenty maunds, or 1,600 ths. of wood and straw, and two bottles of oil were required to consume a healthy body, and $8 \frac{1}{2}$ hours were required for the operation, which even then was virtually incomplete.

IV. On the 10th April last, I examined the person of Beja Gwala, who, with fourteen others, had been wounded two days previously in a zemindari fight, all more or less severely, with swords, garassas, and lathees. In addition to a severe incised wound on the frontal bone, he had a very singular incised wound on the front of the upper third of the right humerus, three inches long, at right angles to the axis of the bone, cutting through the whole mass of muscle, cleanly dividing the shaft of the bone and not touching the brachial artery, veins, and median nerve, and not even scratching the right side. In the absence of any information from the man himself, I am wholly at a loss to account for the wound, how it could hare been inflicted in that strange position, without doing more damage or causing less injury. This difficulty will be understood by imagining the wound on the arm of a well-conditioned man placed before you.

The man must have been on his back (stunned perhaps by the blow on his forehead) and his arm remored from his side; but then how could such a short but deep wound have been inflicted by a sword or garassa?

The remarkable part of the case now follows. In accordance with the rules of the books and schools, I determined on amputating at once, but as it was late in the evening, and there was not the least indication (after three days) of hæmorrhage, I put the arm up in splints and waited for the morning; when it arrived, I found hin looking and fee'ing so comfortable that I hesitated, and knowing the wonderful reparative power of the native, determined on at least trying to save the arm. Strange to say, union took place in a week; it became firmer and firmer, two sequestra separated, and on the 30th May I discharged the man with a granulating cicatrix, an inch long, in the centre of the former wound.

The powers of the arm had been fully tested, for he could cook his own dinner; and this operation, we know, necessitates the kneading of the dough, and the flattening of the chapattee between the two palms, both actions entailing great strain on the bone.

The points to be noted in this case are the difficulty in accounting for the wound, the escape of the vessels and nerve lying close to the divided humerus, and the subsequent re-union of the bone.

The legal point might be raised-Could such a wound, causing so much damage, and avoiding so much further injury, be inflicted at all ?

V. The following case of post-mortem parturition is, I fancy, unique :-

On the 8th of June I examined the body of a woman who was said to have taken opium to avoid the disgrace of an illegitimate pregnancy. Decomposition was well advanced; the stomach was strongly charged with opium. Further examination revealed the following strange appearances: between her thigh lay the inverted uterus, its inverted fundus filled up with distended intestine, and what was its carity fully exposed and quite dry. No placental scar apparent; vagina obliterated. In front of the uterus lay an entire ovum of between 5 and 6 months; placental end lying next to and touching the uterus. The membranes were entire, but dry outside; not a drop of blood or liquor amnii had escaped to stain the charpoy on which she died, and on which she was brought to me. This strange and silent parturition had occurred on the road, unknown to the police, or the bearers who were carrying the body; no vital energies caused it, but simply the irresistible pressure of an intestine distended by putrefaction.

There are cases on record of the contracting uterus completing a delivery interrupted by the death of the woman, but here there was no contracted uterus, but on the contrary a dilated and inverted organ.

Moreover, there could not have been contraction, for the woman had died of a poisonous dose of opium; and it is not likely that a contracted organ would have been wholly inverted.

This case presents many points of medico-legal interest, but the question may be started in limine - "What proofs are there that this was a post, and not a pre-mortem delivery?"

In the first place, the police kyfeut, usually so minute, was entirely silent on the subject of the parturition; if the fuetus 
had been present when the body left the thannah, it would have formed the subject of a distinct notice.

Secondly, had it occurred during life, all the parts would not have been in the position in which they were found; the fretus and placenta would certainly have been detached, and there would have been stains on the bed, either from the liquor amnii or the placental blood. Inversion of the uterus during life could only have resulted from a retained placenta, which there was not; and supposing there had been, the placenta would have been adherent, or at least detached from the fotus. All these indications were wanting.

Thirdly, had the birth and inversion taken place during life, death following soon after, the placental scar must have been apparent, whereas there was not the slightest indication of one ; a dead and bloodless placenta was simply pushed off from a dead and bloodless uterus.

The main point established by this singular case is, that a well advanced fotus may be wholly protruded through the ragina without ans action whatever on the part of the uterus, but this phenomenon could only result from putrefactive distention, to be met with only in tropical climes.

PatNa, 6th June, 1867.

\section{TWO CASES OF DIABETES.}

\section{By Kanikha Nath AcherJee, L.M.S.}

Nobin Chunder Bose a zemindar of 45 years of age, came under my surgical treatment, in March 1865 , for a large abscess in his epigastrium. The abscess was freely opened and poulticed, in his epigastrium. The abscess was freely opened and anent. From the absess to heal, the continual the absence of any tendency of the atrefrom, and the flabby and oozing of a thin and oily matter therefrom, and the I felt a susaplastic character of the granulations of its walls, I felt a suspicion in my mind that the patient was suffering from diabetes. His urine was accordingly examined by the liq: potassæ and cupri : sulph : test, and it was found to contain a good deal of sugar. The patient was thenceforth prohibited to take any food capable of furnishing sugar to the system, and was allowed free use of port,* animal brotbs, and tonics, but his constitution nevertheless became rradually broken and shattered; tution nevertheless became gradually parts of his body, and many abscesses began to form in various parts of his body, and symptoms of pyæmia appeared, shortly after diarrhœa supervened, accompanied by hectic fever, general prostration, and the usual sequelæ of exhausting diseases, and the patient pired after two months from the first appearance of the boils.

The second patient, named Surut Chunder Dutt, a very wealthy, stout "Young Bengal" of 32 years of age, was in the habit of taking richly cooked food, and indulging in the luxuries of this life. Being of a robust constitution, he used to perspire profusely in hot weather, and his body used to be covered with furunculi every year or every other year. Having lived luxuriously during the last hot season, he was attacked with boils in most parts of his body, and with a large carbuncle on before opening the anthrax, the patient was placed his back. Before opening the anthrax, ther it had been crucially divided, poultices and compresses were applied four times a day, divided, poultices and compress liberal supply of port, broth, \&c. and the patient was allowed a liberal supply of port, broth, of But owing to some constitutional derangement, the areoræ of the boils and carbuncle assumed an erysipelatous appearance, the boils and carbuncle ar showed a flabby rough surface, with and the walls of the latter showed a flaby but slight adhesive ill-formed aplastic granulations, having but these eruptions tendency. On making a general comparison of the urine of the with those of the first patient, I suspected that the urine of the second patient was abnormal, and consequently I examined it once or twice by Trommer's and other tests for sugar, of which not the slightest trace was found. In the hot season, whilst his skin continued to act excessively, the eruptions were in active progress, in spite of all treatment. But as soon as the rains set in, and the temperature lowered, the boils healed gradually. On the approach of cold weather, when his profuse sweating stopped, and the kidneys began to excrete largely, my anticipations were verified by his urine being loaded with sugar.

\section{Remarks.}

The appearance of boils in a diabetic patient is a very fatal ymptom. 'This denotes that the diseased and overcharged kidneys cannot carry off the whole of the sugar which is secreted

* This can hardly be called orthodox practice. Port contains from 16 to 34 grains of sugar per ounce,-ED, $, \boldsymbol{I}, \boldsymbol{M}, G$. in the system, and that consequently the superfluous part of it is deposited in the sub-cutaneous cellulo-adipose tissue, which has great affinity for carbonaceous elements. The cutawhich has great affinity for carbore and mal-assimilation of this nourmal element (sugar), becomes irritable and tends to the formation of boils.

The second case is peculiar; boils made their appearance first, and sugar was afterwards found in the urine. This resulted from the patient's having in his system an excess of sugar, which the hot which could kidneys being torpid, a very large quantity of blood (charged with sugar) was attracted towards the cutaneou (charge accumula. neous surface which was then acting the sub-cataneous cellular tion of this unnatural element in the suble to inflammation. tissue, the skin became irritable and liable to inflammation. But as soon as the cold weather approached, his to excrete sugar, the morbid action of his skin stopped, and the patient recovered.

Hitierto the attention of the English physicians has been directed only to the study of the indigenous plants of India, without regard to the compound medicines used by native koberajes. For chronic diseases, such as diarrhœe, dysentery, chronic fever, dropsy, bronchitis, diabetes, \&c., the native physicians certainly possess many valuable remedies. Many cases have been observed where patients suffering from chronic fever or dysenteria, and undergoing English treatment for a month or two, have ultimately recovered by taking a few doses of native medicine. The Sub-Assistant Surgeons, with poor means and possessing slight influence, are hardly able to carry on investigations on this important subject, but the superior officials in the Medical Department ought, I venture to submit, to underin the Medical Departmes with the help of some experienced koberaj. I do not, however, mean to depreciate in any way the value of I do now Faculty to what may well be added to the present store of the British Indian Pharmacopœia

Simla Hills, 15th May, 1867.

\section{RESULTS OF ENDO AND PERI.CARDITIS.}

\author{
By A. Vans Best, M.D., \\ 2nd Assistant-Surgeon, Presidency General Hospital.
}

H. J., aged 23, living at the Sailors' Home, has been in India for five months.

States that eight years ago he had a severe attack of articular rheumatism and pain in his cliest, since which time he has suffered much from palpitation on any exertion, which he has suffered med the has been repeatedly relieved for the time by bleeding in his nose. About five or six months ago he again had, which has joints, and soon afterwards much pain in his chest, which gradually increased, with excessive palpitation and dyspnœa. He was admitted, under Dr.

\section{Ordered-}

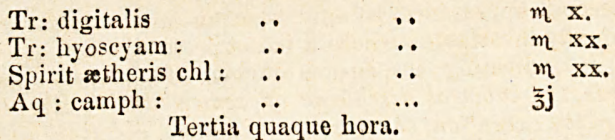

He had also belladonna plasters over the heart, and full doses of morphia at night, with ice, beef-tea, \&c.

When he came under my charge, there was universal dulness over a very extended præcordial region. From the second to the eighth rib on the left side, and across the sternum to fully four inches from its centre towards the left axilla, all this space was excessively painful on percussion.

The motion of the heart was of a peculiar tumbling, jolting character ; the sounis both at base and apex being of a loud rushing character, nearly similar, running into each other, and very irregular in force, four or five powerful beats being followed by several very faint ones. Pulsation very marked iu carotids and subclavian; no venous pulsation. Pulse at wrist from 120 to 140, weak, undecided; no dropsy.

I continued the digitalis for some time, till I feared to press it further. He then had draughts of chloroform, chloric ether, it further. He then had draughts of chloroform, chloria and required 